\title{
Exploring the Place of Literacy, Value Acquisition and Women Empowerment in Mirror Magazine
}

\author{
OFODU, Graceful Onovughe (Ph.D), BORODE, Bolaji Rachael \\ ${ }^{1}$ Institute of Education Faculty of Education Ekiti State University, Nigeria \\ ${ }^{2}$ Department of Curriculum Studies Faculty of Education Ekiti State University, Nigeria
}

\begin{abstract}
This paper explores the place of literacy development, value acquisition and women empowerment in women mirror magazine. The study made use of descriptive survey design. The population for the study consisted of all women in Ekiti State, Nigeria. The sample was 300 women purposively selected for the study. The instrument used for data collection was a self-designed questionnaire of 25 items which was constructed to elicit responses from the subjects on their views on how the magazine has impacted their lives. The reliability was ensured using Cronbach alpha and a reliability coefficient of 0.68 was obtained.Two research hypotheses were formulated and four research questions were generated to guide the study. The result revealed that the magazine has been a literacy resource that has helped women in developing the skills of reading, writing, speaking, and inspiration for child training. Many women have used the knowledge gained from the magazine to transform their value acquisition thereby transforming the value system and orientation of their children. The findings revealed that some women do not read the magazine at all, most women who read the magazine are educated and marital status has slight impact on readers' ability. The study recommended among others that women should show more interest in reading the magazine.
\end{abstract}

Keywords: Marital status, Educational qualifications, Literacy resources, Value, Empowerment

\section{Introduction}

We live in a rapidly changing world where the values we once cherished and promoted are no longer in vogue. Every day we find negative influences and declining moral values everywhere we turn to, from television, movies, internet to magazines (Ladd, 2003). Where then can we turn to for help? Who is willing to salvage the upcoming generation from the ruins in our societies?

Women possess a rare form of strength. They make up a high percentage of any society. Women continuously build values and visions into the lives of children, which is why they are called nation builders. The place of women in any society cannot be glossed over. When women are empowered in all spheres of life, they impart and impact lives positively. In fact, the multiplied effects are enormous. Studies have shown that women play important roles in inculcating a culture of reading and values in children (Okegbile, 2008; Sanota, 2011,Nwagbara, 2011).

One of the monthly magazines which provides good reading opportunities and links people with information on a wide range of issues is the Women Mirror magazine. The magazine is easy to read. It provides opportunity for intensive and extensive reading. A closer look at the magazine reveals that it promotes lifelong learning, reading for pleasure and literacy for all. It is a monthly magazine published by the Deeper Life Christian Ministry for the total and all round development of the women folk. The magazine was probably born out of the need to meet the multifaceted needs of women in the growing church where most women are likely to attend to the needs of children, cope with the responsibilities of working and family chores. Moreover, the churchrecognizes the universal roles of women in the well-being and maintenance of the family which is microcosm of the society and believes strongly that a transformation of the women is a transformation for survival, recovery and reconstruction of the society.

Every edition of the magazine has colourful, captivating and fascinating cover story. This is closely followed by the Feature Piece, Treasure Chest, Did you know that? Bible Quiz, Quotable Quotes, Tracts of life, Manuals, The Virtuous woman, Child training and Reading the Bible through the Year to mention a few. The available information if properly read could be used for self-improvement, empowerment and attitudinal change.Perhaps, this is the reason for the overwhelming demand for the magazine by women and men in banks, schools, offices, homes, eateries, hospitals, tertiary institutions and different places.The magazine is easy to read. It provides opportunity for intensive and extensive reading.

On the other hand, the researchers feel that because women have several roles to play both at home and in offices, these roles demand a lot of attention from them to the extent that many may not have time to read the magazine, and so it may or may not have impacted their lives. If it has impacted their lives, in what areas has it done so and to what extent has it? It is against this background that these researchers therefore felt that there is 
the need to investigate if women are actually reading this monthly magazine and the impact it has on their literacy development, value acquisition and empowerment.

\section{Statement of the Problem}

In realization of the place of women, international agencies (the World Bank, UNESCO, UNDP and UNICEF) made substantive agreement to uplift the status of women. In Nigeria, the Federal Government has taken various drastic steps to stop the spread of illiteracy which affects women most. As an agent of socialization, the church decides to join in the fight against illiteracy,discrimination against women, discourage inequality, provide functional literacy to women, established the women ministry and women mirror. In spite of the overwhelming demand for the women mirror magazine, observation and experience have revealed that many women do not read the magazine may be because they are pre-occupied with house chores which reduce the meager time at their disposal. Could the problem be attributed to the level of education or marital status?

To this end, this study attempts to find answers to the following questions:

1.How often do women read the women mirror magazine?

2.To what extent has the Mirror influenced literacy development, value acquisition and empowerment among women?

\section{Hypotheses}

Ho1: There is no difference between the educational qualifications of women and reading the women mirror magazine

Ho2: There is no difference between the marital status of women and reading the women mirror magazine

\section{Review of Related Literature}

Literacy is a potent weapon for fighting poverty, diseases, ignorance, and moral bankruptcy among people. Similarly, literacy is considered a vital tool for the emancipation and empowerment of women. Sebangane and Kololo (2011) opine that from time immemorial women are considered inferior to men in all spheres of influence. They added that women are socially, economically and politically disadvantaged not necessarily by men but by illiteracy, their inability to read, write and engage in literacy activities have put them at cross purposes with their male counterparts. The effects of illiteracy culminate in high percentages of domestic violence among women, less right to decide the number of children, timing and spacing of children, inability to train their children and promotion of uncultured and violent children. Development agencies have discovered that two key indicators of women's ability to live long in many developing nations are: accessibility to clean water and literacy.

In a survey of two thousand people, Thorpe (2009) reports that women are avid readers who cannot stop reading (especially fiction) a book once they start and they do so once for a long list of books yearly while men admitted they never complete reading a book. Similarly, Weiner (2007) reports the reasons for the gender gap are that psychological theories support women possess a more empathetic nature and emotional powers than men; others say that at early age, girls develop this trend because they are opportune to sit still.

Oshun (2011) investigated the extent market women in Lagos state have exercised their rights to education with regard to literacy programmes. A total of five hundred women formed the target population. Structured interview questions were used for gathering information. All the four hypotheses formulated were rejected as results revealed that majority of the market women were unaware of the existence of continuing education centres that offer literacy programmes. They were unaware of their rights to education under the literacy programmes, and they do not make enough profit to consider returning to school to back up their aspirations to leadership positions, neither have they taken advantage of the continuing education centres.

In traditional Nigerian society, the process of socialization called indigenous education is seen as a means of entrenching values and attitudes. Osokoya (1997) asserts that the most crucial aspect of indigenous education was its relevance to individuals and the societal needs and aspirations. Children learnt by doing things. Young ones were corrected whenever a wrong sound or speech was made to the learning of any adult. Through story-telling, poetry and incantations for building a good character in the child, the responsibility was not left to the child's parents alone. Distance relatives, peer groups and other members of the community were expected to contribute their quota (Osokoya 1997). The major learning processes were by observation, imitation and participation. This intellectual training included the study of local history, legends, local geography, poetry, riddles, proverbs and story-telling.

Olaogun (2012) commenting on this type of education states that, at childhood, children receives training in toileting, eating, socialization and good behaviour from parents, siblings, relatives and friends. He adds that they watch their mothers closely, learn by imitation, learn the first language (that is the mother tongue) and learn the meaning of smiles, cries and frowns. 
In modern times, other means by which values are communicated includestorytelling, quizzes and education/literacyprogrammes.Although home videos seem to eradicate the value of storytelling in many Nigerian homes, parents should avail themselves the opportunity of explaining the positive and negative values that should be discouraged and encouraged among children as they watch such programmes. Eziaku (2010) blames the poor image of Nigerians by foreigners on the decadence in societal values, corruption and the wrong attitude by many Nigerians to work, education and government properties. He opines that literacy holds the vital key to the transformation of societal values and the educated adolescents could serve as vanguards of value orientation.

Empowerment is conceived as the ability to direct and control one's life (UNESCO 2008). Kiah 2011 opines that empowerment begins and goes beyond formal education. The family, community and cultural experiences are all essential elements in empowering people to gain control over their own lives. However, education and literacy are to a large extent the precursors to empowerment. Literacy is central to knowledge acquisition and empowerment in any society. Thus, efforts are made to promote literacy activities through educationso that individuls can acquire knowledge, become empowered and use such knowledge to improve the quality of life and the society (Kolawole\&Kolawole, 2011).

The Nigerian woman is an enterprising and multi-tasked woman. FAWE (2001) reports claim that educating girls and women is the single most important investment that yields maximum returns for development, which translates into decrease in infant mortality rates, a higher probability of children getting good education and most importantly, women becoming income generators, thus increasing the economic power-base of the family (Adu-Yeboah\&Kpeglo, 2010). Similarly, Adedokun (2011) in her study found that literacy is a weapon for fighting poverty, diseases, andignorance and when all these are fought, an average woman becomes empowered to participate actively in issues of development in her community.

From the review of related literature, it can be seen that the ties among the three variables of this study is so strong that they cannot be easily broken or ignored. Literacy is a learning skill as well as a survival strategy in our global community that is highly infested with valueless messes that entangle both the young and the old. As a key to unlocking the essential components of successful living, women can be empowered to develop themselves and everyone who come in contact with them.

\section{Methodology}

The study made use of descriptive survey design. The population for the study consisted of all women in Ado-Ekiti, the capital city of Ekiti State, Nigeria. The sample was 300 women purposively selected for the study. A self-designed questionnaire of 25 items was constructed to elicit responses from the subjects on their views on how the Women Mirror magazine has impacted their lives. The instrument had two sections: A and B. Section A dealt with the bio data of the respondents while Section B required respondents to indicate how the magazine has empowered their literacy development, value acquisition and empowerment. The questionnaire items were validated by experts in literacy education in the Ekiti State University, Ado-Ekiti. To ensure the reliability of the items, they were pretested on twenty (35) women inEkiti south west and west local government areas, and a correlation coefficient of 0.68 was obtained and this was deemed good and reliable. Copies of the questionnaire were personally distributed by the researchers with thehelp of some research assistants. Three hundred (300) copies were distributed while only 250 were valid. Data collected were analyzed using percentage counts, t-test and ANOVA.

\section{Results}

Table 1: Bio data of Respondents

\begin{tabular}{|l|l|l|l|l|l|}
\hline \multicolumn{1}{|c|}{ Qualification } & \multicolumn{1}{c|}{ N } & \multicolumn{1}{c|}{ M } & \multicolumn{1}{c|}{ Marital Status } & \multicolumn{1}{c|}{$\mathbf{N}$} & \multicolumn{1}{c|}{} \\
\hline BELOW WASSCE & & & & & \\
WASSCE & 71 & 28 & SINGLE & 70 & 28 \\
NCE/OND/HND & 37 & 15 & MARRIED & 131 & 52 \\
B.A/B.SC/M.SC & 70 & 28 & OTHERS & 49 & 20 \\
TOTAL & 72 & 29 & TOTAL & 250 & 100 \\
& 250 & 100 & & & \\
\hline
\end{tabular}

Table 1 shows that majority of the respondents are educated women ( $29 \%$ are degree holders and $28 \%$ are NCE, OND and HND holders). It also shows that majority of the readers are married women (52\%). Research Question1: How often do you read the women mirror magazine 
Table 2: Frequency Level of Reading the Magazine

\begin{tabular}{|l|c|c|}
\hline & $\mathbf{N}$ & \% \\
\hline Very often & 72 & 29 \\
Often & 71 & 28 \\
Rarely & 42 & 17 \\
Never & 6 & 2 \\
Others & 59 & 24 \\
Total & 250 & 100 \\
\hline
\end{tabular}

Table 2 indicates that $29 \%$ of the respondents read the magazine very often while $28 \%$ read it often. $17 \%$ indicated that they rarely read while $2 \%$ indicated they have never but $24 \%$ did not fill this portion.

Research Question 2: To what extent has the Mirror influenced literacy development, value acquisition and women empowerment?

Table 3: Extent to which the Mirror has influenced literacy development, value acquisition and Women Empowerment

\begin{tabular}{|c|c|c|c|c|c|}
\hline $\mathbf{S} / \mathbf{N}$ & ITEMS & $\begin{array}{c}\text { SA } \\
\%\end{array}$ & $\begin{array}{l}\mathbf{A} \\
\%\end{array}$ & $\begin{array}{c}\text { SD } \\
\%\end{array}$ & D \\
\hline 1 & I feel like reading the magazine each time it is published. & 64 & 33 & 2 & 1 \\
\hline 2 & $\begin{array}{l}\text { I have to read so many parts of the Bible in order to answer the quiz section } \\
\text { I am fascinated to read because of the stories in each feature }\end{array}$ & 34 & 37 & 8 & 22 \\
\hline 3 & I am motivated to read other literacy resources because of the magazine & 43 & 41 & 7 & 8 \\
\hline 4 & $\begin{array}{l}\text { I cannot read it because of the difficult words in most of the features } \\
\text { I am prompted to write down the points from each feature }\end{array}$ & 26 & 43 & 10 & 21 \\
\hline 5 & I can talk about great personalities because of the magazine & 6 & 6 & 45 & 44 \\
\hline 6 & I am attracted to read the magazine because of the pictures & 25 & 46 & 9 & 20 \\
\hline 7 & I value the child training aspect of the magazine greatly & 48 & 39 & 3 & 9 \\
\hline 8 & & 35 & 22 & 15 & 28 \\
\hline \multirow[t]{3}{*}{9} & & 66 & 28 & 2 & 4 \\
\hline & $\begin{array}{l}\text { To what extent do you agree that the magazine has influenced your value of } \\
\text { the following : }\end{array}$ & & & & \\
\hline & & VG & $\mathbf{G}$ & $\mathbf{H}$ & $\mathbf{N}$ \\
\hline 10 & Diligence & 70 & 28 & 4 & 8 \\
\hline 11 & Punctuality & 55 & 40 & 3 & 2 \\
\hline 12 & Child Training & 71 & 24 & 2 & 3 \\
\hline 13 & Cleanliness & 70 & 27 & 1 & 2 \\
\hline 14 & Time management & 62 & 31 & 2 & 4 \\
\hline 15 & Foresight. & 62 & 32 & 4 & 3 \\
\hline \multirow[t]{2}{*}{16} & Integrity. & 64 & 31 & 2 & 4 \\
\hline & $\begin{array}{l}\text { To what extent do you agree that the magazine has empowered you in the } \\
\text { following areas: }\end{array}$ & VG & $\mathbf{G}$ & $\mathbf{H}$ & $\mathbf{N}$ \\
\hline 17 & Home management & 67 & 30 & 1 & 2 \\
\hline 18 & Finance & 60 & 33 & 4 & 3 \\
\hline 19 & Spiritual life & 76 & 21 & 1 & 2 \\
\hline 20 & Leadership qualities & 61 & 32 & 2 & 5 \\
\hline 21 & Career & 61 & 35 & 1 & 3 \\
\hline 22 & Health & 65 & 30 & 2 & 3 \\
\hline 23 & Academics & 58 & 34 & 4 & 3 \\
\hline 24 & Marriage & 68 & 26 & 3 & 3 \\
\hline 25 & Self-employment & 54 & 33 & 6 & 7 \\
\hline
\end{tabular}

Table 3 shows that the mirror has greatly helped women to read wide $(71 \%)$ because it is frequently published $(97 \%)$, the stories are fascinating $(84 \%)$ and the pictures are captivating $(57 \%)$. Again, it shows that women acquire a lot of values when they read the magazine, as majority of them indicated that that it has greatly and very greatly influenced their value acquisition. Similarly, it shows that women have been empowered greatly in all aspects of life.

\section{Hypotheses Testing}

Hypothesis One: There is no difference between the educational qualifications of women andreading the women mirror magazine 
Table 5: ANOVA Summary of Qualification and Readers of Women Mirror

\begin{tabular}{|l|l|l|r|r|c|}
\hline \multicolumn{1}{|c|}{ Source } & \multicolumn{1}{|c|}{ SS } & \multicolumn{1}{c|}{ Df } & MS & Fcal & Ftab \\
\hline Between Groups & 298.86 & 2 & 149.45 & 2.42 & 3.00 \\
Within Groups & 10792.65 & 175 & 61.67 & & \\
Total & 11091.51 & 177 & & & \\
\hline \multicolumn{1}{|c|}{$\mathbf{p}>\mathbf{0 . 0 5}$} & & & & & \\
\hline
\end{tabular}

Table 5 shows that Fcal (2.42) is less than Ftab (3.00) at 0.05 level of significance. The null hypothesis is accepted. Therefore, there is no difference between the readers of the magazine and their educational qualifications.

Hypothesis Two: There is no difference between the marital status of women and reading the women mirror magazine

Table 6: t-test showingMarital Status and Reading Women Mirror

\begin{tabular}{|l|l|l|l|l|l|l|}
\hline \multicolumn{1}{|c|}{ Marital Status } & N & \multicolumn{1}{c|}{ Mean } & SD & Df & Tcal & t-tab \\
\hline Single & 70 & 82.04 & 8.13 & 198 & 1.99 & 1.96 \\
Married & 130 & 84.32 & 7.46 & & & \\
\hline
\end{tabular}

Table 6 shows that tcal (1.99) is greater than ttab (1.96) at 0.05 level of significance. The null hypothesis is rejected. Therefore, there is difference between the readers of the magazine and marital status.

\section{Discussion}

The findings of the study revealed that many women read the magazine although a small number indicated they rarely read it. To some extent this confirms Thorpe (2007) and Weiner (2007) submissions that women are avid readers.

Moreover, the findings of this study have clearly revealed that the women who read the magazine are mostly educated ones. This simply translates to the fact that they are literate. No wonder they are fascinated by the stories and the pictures. Literacy is power. It unlocks the sterling potentials in women and enables them to effectively discharge their duties. Literacy develops by an individual's participation in a variety of literacy experiences (Cooper and Kiger (2006)). The elements of literacy: listening, speaking, reading, writing and thinking continuously develop. The process of literacy development is unending. The level of interactions and exposure to literacy resources determine the extent of literacy development and skills acquisition of an individual.

Again, it shows that women acquire a lot of values when they read the magazine, as majority of them indicated that that it has greatly influenced their value acquisition. The implication of this finding is thatthese values can be inculcated in the lives of their children because a woman is the most fundamental part of the growth and development of any child. Children are closest to their mothers than their fathers. Mothers are vested with the ability to mold and nurture children with great and inestimable attitudes, behaviour, values within the family. Perhaps, this informed the sociologist submission that it is the number one agent of socialization for everyone born into the world. The reason for this assertion is not far-fetched. All basic, core and fundamental values are inculcated in children within the family. First among them is physical values such as simple etiquettes like waking up early, doing simple chores, basic hygiene and hard work. Again, moral values of truthfulness, honesty and respect for all are ingrained in the family circle such that falsehood is alien to children. The social values of cordial and peaceful interpersonal relationships with siblings, other family members and outsiders are all taught within the family. Last but not the least is spiritual values. Here, love and respect for God is taught and the best way to show this is to respect and love the humans all around, thereby paving way for harmonious relationship within the citizenry (Ofodu, 2012). What these translate to is that the value a parent holds or places on certain aspects of life would determine the value the offspring will hold (Olaogun, 2012). If a parent is a deviant or fails to transmit or display appropriate behaviours, he is directly or indirectly transmitting the negatives to the offspring.

In the same vein, the findings indicatedthatwomen are empowered greatly in almost all aspects of life by reading the magazine.This simply means that many readers of the magazine get empowered whenever they read the magazine without giving them money to begin a business. This magazine in essence, is one of the veritable means by which the church is fulfilling some of the Millennium Development Goals such as eradication of extreme poverty, promotion of gender equity and empowering women, improvement in maternal health and combating HIV/AIDS, malaria and other diseases. 
However, it was revealed that no difference existed between the readers of the magazine and their educational qualifications. This is not surprising because the most important thing is for women to be education and with that the doors are open to her acquire all the literacy skills she can acquire or learn.

Finally, the study proved that there is difference between the readers of the magazine and marital status. This shows that women who read the magazineare mostly married women going by the mean score. This is surprising because the Holy Book affirms that the married cares for the things that are of the world while the unmarried cares for the things that belong of the Lord. The single women have ample time to read while the married have a lot of chores to carter for that could possibly hinder them from reading, yet in this study the married still had much interest in reading.

\section{Conclusion and Recommendations}

The investigated the place of literacy, value acquisition and women empowerment in women mirror magazine. It found that the magazine has greatly influenced reading literacy skills, values and empowered the educated, married and single women. Based on this, it was recommended that more women should be exposed to the reading of the magazine since it has the ability to assist women in developing their literacy skills. Furthermore, both the married and unmarried should devote time to reading the magazine since the benefits of reading are immeasurable.

\section{References}

[1]. Adedokun, M.O. (2011). Literacy: A potent tool for women empowerment. International Review of Social Sciences and Humanities. Vol. 1, No. 2 (2011), pp. 65-72 www.irssh.com ISSN 2248-9010 Accessed 31/07/2013

[2]. Adu-Yeboah, C.\&Kpeglo, C.S. (2012).Crossing the boundary: Women students in male dominated fields in higher education.In D.D. Kuupole\& Isaiah Bariki (Eds) Applied social dimensions of language use and teaching in West AfricaGhana: The University Press 299-310

[3]. Eziaku, U. (2010).Education and the reorientation of the value system of the Nigerian adolescents.Book of Abstract $12^{\text {th }}$ Biennual National Conference of the Reading Association of Nigeria, $18^{\text {th }}-21^{\text {st }}$ August, 2010

[4]. FAWE (2001).Girls education and poverty eradication: FAWE's response. Paper presented by FAWE secretariat at the Third United Nations conference on the least developed countries, 10-20 May, 2001, Russels, Belgium

[5]. Ladd, K. (2003). The power of a positive mom. Benin: Christian Publications

[6]. Kiah, R. (2011). Do not all words have weight: Empowerment through orality. 7th Pan-African Reading for All conference Book of Abstract. 11th-14th July 2011. University of Botswana

[7]. Kolawole,C.O.O.\&Kolawole, A.O. (2011). Literacy, knowledge and empowerment in a multilingual society: What options for language choice? The $7^{\text {th }}$ Pan-African Reading for All conference Book of Abstract. 11th-14 $4^{\text {th }}$ July 2011. University of Botswana

[8]. Nwagbara, C. (2011). Literacy and gender parity: Strategies for balance. Literacy and Reading in Nigeria. 13.1.78-86

[9]. Ofodu, G.O.(2012). Family literacy: An essential component of peaceful co-existence in Nigeria. Literacy and Reading 14.1.

[10]. Okegbile, A.S. (2008). Female education in Northern Nigeria and intellectual stimulation of the child's home for the achievement of Millennium Development Goals. In A.S. Okegbile, S.A.E. Apara, E.O. Ogungbe, N.S. Talla\& M.H. Mohammed (Eds.) Education and development in Northern Nigeria Niger: Faculty of Education and Arts, IBB University. 239-247

[11]. Olaogun,J.A.(2009). Pandemonium in the land: social value system to the rescue. $34^{\text {th }}$ inaugural lecture series held on $9^{\text {th }}$, october 2012. Ado-Ekiti: Ekiti state university.

[12]. Oshun, G. O. (2011). Right to education: Government policy on literacy programmesand literacy level of market women in Lagos state. $7^{\text {th }}$ Pan-African for All conference Book of Abstract. 11th-14 $4^{\text {th }}$ July 2011. University of Botswana

[13]. Osokoya, I.O. (1997). 6-3-3-4 Education in Nigeria: History, strategies, issues and problems Ibadan: Laurel Educational Publishers

[14]. Sanota, D. (2011). Parents in academia and their role in promoting a reading culture. $7^{\text {th }}$ Pan-African for All conference Book of Abstract. 11th-14 ${ }^{\text {th }}$ July 2011. University of Botswana

[15]. Sebangane, O. \&Kololo, P. (2011).Women empowerment $7^{\text {th }}$ Pan-African for All conference Book of Abstract. 11th-14 $4^{\text {th }}$ July 2011. University of Botswana

[16]. Thorpe, V. (2009). Why women read more than men. The Observer 21 March, 2009.www.theguardian.com>culture>books

[17]. UNESCO (2008).Literacy and rural women.http//:UNESCO doc.unesco.org

[18]. Weiner, E. (2007). Why women read more than men. 05 September, 2007 www.npr.org $>$ Arts \& Life> Books 